This is the author's final, peer-reviewed manuscript as accepted for publication. The publisher-formatted version may be available through the publisher's web site or your institution's library.

\title{
Dilemmas, conspiracies, and Sophie's choice: vignette themes and ethical judgments
}

Peter E. Mudrack and E. Sharon Mason

\section{How to cite this manuscript}

If you make reference to this version of the manuscript, use the following information:

Mudrack, P. E., \& Mason, E. S. (2013). Dilemmas, conspiracies, and Sophie's choice:

Vignette themes and ethical judgments. Retrieved from http://krex.ksu.edu

\section{Published Version Information}

Citation: Mudrack, P. E., \& Mason, E. S. (2013). Dilemmas, conspiracies, and Sophie's choice: Vignette themes and ethical judgments. Journal of Business Ethics, 118(3), 639653.

Copyright: @ Springer Science+Business Media Dordrecht 2013

Digital Object Identifier (DOI): doi:10.1007/s10551-012-1611-0

Publisher's Link: http://link.springer.com/article/10.1007/s10551-012-1611-0

This item was retrieved from the K-State Research Exchange (K-REx), the institutional repository of Kansas State University. K-REx is available at http://krex.ksu.edu 
Dilemmas, Conspiracies, and Sophie's Choice: Vignette Themes and Ethical Judgments

Peter E. Mudrack

Department of Management, Kansas State University

E. Sharon Mason

Brock University

KEY WORDS: Ethical Judgments; Vignette Themes; Literature Review 


\title{
Dilemmas, Conspiracies, and Sophie’s Choice: Vignette Themes and Ethical Judgments
}

\author{
Abstract \\ Knowledge about ethical judgments has not advanced appreciably after decades of research. \\ Such research, however, has rarely addressed the possible importance of the content of such judgments; \\ that is, the material appearing in the brief vignettes or scenarios on which survey respondents base their \\ evaluations. Indeed, this content has seemed an afterthought in most investigations. This paper closely \\ examined the vast array of vignettes that have appeared in relevant research in an effort to reduce this \\ proliferation to a more concise set of overarching vignette themes. Six generic themes emerged from this \\ process, labeled here as Dilemma, Classic, Conspiracy, Sophie’s Choice, Runaway Trolley, and Whistle \\ Blowing. Each of these themes is characterized by a unique combination of four key factors that include \\ the extent of protagonist personal benefit from relevant vignette activities and victim salience in vignette \\ descriptions. Theme identification enabled inherent ambiguities in vignettes that threaten construct \\ validity to come into sharp focus, provided clues regarding appropriate vignette construction, and may \\ help to make sense of patterns of empirical findings that heretofore have seemed difficult to explain.
}

RUNNING HEAD: Vignette Themes (Revised) 


\section{Dilemmas, Conspiracies, and Sophie’s Choice: Vignette Themes and Ethical Judgments}

Ethical judgments refer to individual determinations of the appropriateness of ethically questionable courses of action (Reidenbach and Robin, 1990; Robin, Reidenbach, and Babin, 1997; Sparks and Pan, 2010). Although the concept seems straightforward, decades of empirical investigation have failed to advance knowledge appreciably given tendencies, for example, toward replication of wellestablished findings (Mudrack \& Mason, 2012). As suggested by these authors, an overall absence of meaningful results may be attributable to a neglect of the actual content of ethical judgments; that is, to precisely what survey respondents are evaluating. This content usually involves one or more brief vignettes or scenarios in which an ethically questionable activity has been carried out or witnessed. However, investigators rarely, if ever, provide substantive reasons for using specific vignettes, and the following example is typical: "Five scenarios ... constructed by the researchers (or adopted from previous research) were employed in the study” with no further explanation offered other than these scenarios “represented” various “problem categories” (Davis, Andersen, \& Curtis, 2001, p. 41). To further confound matters, even when the same basic vignette has been used in different studies, salient vignette details often differ without acknowledgement yielding variations and permutations without apparent rhyme or reason. A likely consequence of this seemingly haphazard diversity is that any insight gleaned about ethical judgments might very well be situation-specific and applicable only to the vignette(s) examined rather than generalizable (Collins, 2000, p. 16). The purpose of this paper is to examine vignette content in some depth in order to identify some overarching themes that may be present in the considerable vignette diversity that characterizes the ethical judgments literature. Six themes will be discussed later. Theme identification may be important to the extent that it provides an organizing framework that permits more focused research, and thus an accumulation of knowledge, based on coherent groupings of vignettes.

Our point of departure was the observations of Mudrack and Mason (2012) based on their analysis of a few specific vignettes that suggested four criteria (e.g., victim salience) on which these might meaningfully be classified. With little to no prior discussion in the literature regarding vignette 
content, there seemed no obvious alternative approach that would help to make sense of vignette proliferation and diversity. A closer examination of their vignettes using these analytic criteria led us to identify two distinct themes, Dilemma and Classic. These criteria captured salient shared characteristics within each theme while also permitting elucidation of marked differences between themes. We then extended this work by using the same four criteria in the context of a comprehensive review of vignettes used in ethical judgment studies. This analysis yielded four additional vignette themes: Conspiracy, Sophie’s Choice, Runaway Trolley, and Whistle Blowing (see Table).

\section{INSERT TABLE ABOUT HERE}

In conducting the above investigation, we also noted that vignette themes are frequently characterized by inherent ambiguity, a phenomenon we illustrate with an often-used vignette relevant to bribery. This vignette has undergone many unexplained permutations through various investigations. We elaborated this issue in the literature and offered suggestions for providing clarity. Evidence was then presented for asserting the practical research value of the six identified themes both in offering a conceptual overlay to reconcile divergent and seemingly uncoupled findings and also in providing guidance regarding data aggregation across vignettes. These processes were illustrated using existing findings of relationships between ethical judgments and both Machiavellianism and locus of control. We concluded by suggesting the possibility that an awareness of vignette themes may provide a path forward that leads toward a deeper understanding of ethical judgments than has so far been available. Future research is needed to ascertain the value of this promising direction.

\section{Investigating Ethical Judgments}

As mentioned earlier, in the study of ethical judgments, respondents are presented with one or more vignettes that depict an ethically questionable activity, and then evaluate the appropriateness of the action described with one or more survey items (e.g., to what extent is this “fair” or “unfair”?). Such

procedures differ from those followed in typical survey research. To assess, for example, personality traits or job satisfaction, respondents themselves furnish the frame of reference. They are asked to provide insight into themselves, or something (e.g., job) or someone (e.g., spouse or coworker) with which they 
are familiar. In contrast, ethical judgments cannot occur until researchers provide the frame of reference; that is, something to judge. Respondents must be presented with specific activities performed by specific persons in specific ways before it is even possible to offer evaluations. Ethical judgments, therefore, are inseparable from the precise details of what is being judged. In this atypical abstraction inherent in vignettes, and the absence of lived, felt experience, these details may become especially crucial.

Although actual vignette features are the obvious starting point for ethical judgments, these seem an afterthought in many empirical investigations. As noted by Mudrack and Mason (2012), researchers seldom offer definitive reasons for using the specific vignettes; a practice that can be traced back to Reidenbach and Robin’s (1990) seminal work. Many papers, in fact, omit vignettes altogether (e.g., Chiu, 2003; Chiu and Erdener, 2003; Cohen and Bennie, 2006; Razzaque and Hwee, 2002; Schwepker and Ingram, 1996; Shafer, 2008), while others merely allude to vignette content (e.g., "offer monetary bribe to buyer”, "indirect material bribe to buyer”; Stevenson and Bodkin, 1998, p. 50). Indeed, investigators generally tend to focus far more on "format" (which combinations of survey items to use) than on “content” (what precisely is being judged). This seemingly misplaced focus, however, may be both understandable and inevitable given the difficulties associated with vignette selection.

Persons interested in collecting data on ethical judgments are immediately faced with the daunting task of selecting from the vast array of vignettes that have appeared in the published literature (or developing their own stimulus materials), and little guidance is available for making appropriate choices. Even investigators who focus on a specific topic such as bribery have many different options at their disposal. For example, vignette protagonists could willingly offer bribes, bribes could be ordered by supervisors, or would-be bribe recipients could demand payment. What seems urgently needed here is parsimony; specifically, identification of commonalities in vignettes that would enable these to be classified or categorized into, ideally, one of a relatively few overarching themes. Empirical investigations could then explore ethical judgments in the context of different themes in some depth, build directly on prior research, and thus perhaps create a more meaningful understanding of such judgments than has heretofore been available. We begin by looking more closely at the specific vignettes discussed 
by Mudrack and Mason (2012) and use four criteria on which vignettes might usefully be classified to identify two separate themes, Dilemma and Classic.

\section{Dilemma and Classic Themed Vignettes}

With the aforementioned goal of parsimony, vignette themes cannot realistically be based on details that seem almost limitless in their variety such as the specific questionable activities presented (e.g., bribery, price-fixing), settings for activities discussed (e.g., auditing, retailing), the specific roles of vignette protagonists (e.g., store manager, accountant), or protagonist demographic characteristics (e.g., age, gender). In attempting to develop systematic vignette parameters, Mudrack and Mason (2012) noted the potential relevance of three factors (protagonist freedom of action, extent of personal benefits accruing to protagonists, victim salience) that provide possible criteria for theme identification in the context of a vignette used by Shafer (2002). In this situation, the accountant protagonist was ordered to perform a questionable act (backdate sales invoices), feared losing his job if he refused, and did not benefit in any tangible way by this action (beyond being keeping his job). Moreover, the vignette was

silent on any harm resulting from this action or victims affected by it. As "this plan would increase gross profit and pretax income by approximately \$100 000” (p. 260), the harm presumably involved shareholders and possible investors misled about company performance.

The protagonist in this situation has clearly been put into a difficult position. Not only would the accountant be doing something that likely seems wrong to him (and that certainly lacks tangible rewards regardless), he might also serve as a convenient scapegoat if caught, with the supervisor who issued orders being able credibly to deny involvement. Under such conditions, what is the right thing to do? Should the accountant simply refuse a direct order, and risk unemployment? Alternatively, should he comply, however reluctantly, get his "hands dirty”, and risk possible criminal prosecution later? This situation represents a genuine dilemma in that there are two possibilities available, neither of which is practically acceptable. The vignette protagonist in this situation is literally caught on the "horns of a dilemma”, where the sharp points of the two metaphorical "horns” are both destructive. As suggested by Mudrack and Mason (2012), Shafer’s (2002) respondents may have evaluated the "wrong protagonist”, 
which could explain the general absence of hypothesis support in that study. These respondents judged only the ethics of the accountant who followed orders but not the supervisor who issued orders that deliberately put someone in a compromising position, and who may even technically be guilty of extortion; that is, obtaining a service through coercion or threats, whether explicit or implicit. Indeed, the supervisor's ethics seem more questionable than those of the accountant.

Rather than simply speculate about the relative ethics of different vignette protagonists, we asked a sample of 94 senior undergraduate business students to read the vignette used by Shafer (2002), and to evaluate the actions of both the accountant and the supervisor on two seven-point scales anchored by unethical (seven points) and ethical (one point). Regardless of which protagonist was judged first (there were two versions of the survey), the supervisor clearly emerged as "more unethical" (mean score $=6.22$ ) than the accountant (mean score $=3.87$ ). Shafer's (2002) respondents, in contrast, who had only one protagonist from which to choose, generally indicated that the accountant’s actions were "clearly unethical” (p. 254; lowest reported mean score $=9.03$ out of 10, minimum score of zero). On the sevenpoint scale used here, such a score is equivalent to 6.38. Of course, what is unknown is whether any of Shafer's (2002) respondents happened to notice the mitigating circumstances of supervisory orders that apparently seem obvious once pointed out, and factored this into their evaluations of the accountant. Also unknown is the extent to which these respondents made judgments based on the totality of the situation that included duress applied by the supervisor, even though they were only asked to judge the accountant. Just because the significance of evaluating the “correct protagonist” has apparently gone unnoticed by researchers does not necessarily imply that respondents likewise failed to notice this. The possibility that not all respondents evaluated the same event in the same way calls into question the construct validity of Shafer's (2002) vignette--a reasonable but until now unexplored explanation for hypothesis non-support. Regardless, although it may have factored into their ethical judgments, Shafer's respondents also did not definitively evaluate the most ethically questionable action described (or implicit) in the story, and this may be another vignette characteristic relevant in theme determination.

Many investigations have employed similar Dilemma vignettes with low victim salience in which 
protagonists whose freedom of choice is restricted do not derive personal benefits from what is likely not the most ethically questionable action implied in the vignette. For example, Vignettes 3 and 18 (Barnett, Bass, and Brown, 1994) involved, respectively, an auditor ordered to destroy papers and a manager who authorized, apparently not in writing, a subordinate to violate rules. Other examples of Dilemma vignettes appear in the Appendix. In each of these situations, investigators did not note the possible significance of protagonists, for example, having reduced “degrees of freedom”, and provided no indication that such vignette details were chosen for specific conceptual reasons. As discussed, researchers seldom if ever mentioned any reasons whatsoever for using particular vignettes.

Mudrack and Mason (2012) contrasted the Dilemma vignette used by Shafer (2002) with the three Classic vignettes employed in Reidenbach and Robin’s (1990) foundational research and elsewhere. One of these latter involved an auto dealer who superficially fixed a customer's problem vehicle until the warranty expired, and then charged full price actually to resolve the problem (the Appendix describes other vignettes). In this situation, the protagonist has complete freedom of action and is not subject to outside pressures from supervisors or clients. For example, the auto dealer chose to stall until the warranty expired before conducting needed repairs, received no "requests" or orders to this effect, and also stands to benefit personally by earning more money than otherwise would have been earned. Moreover, Classic vignettes explicitly identify victims of actions that seemed the most questionable present in the case as written; for example, the vehicle owner now required to pay full price for repairs.

On the three criteria for theme identification identified by Mudrack and Mason (2012), plus the additional issue of whether respondents have evaluated the most ethically dubious action described, Dilemma and Classic vignettes differ profoundly (see Table).

It should be noted that there is not necessarily anything wrong with Dilemma vignettes in the context of ethical judgments. Researchers, however, should be fully aware of the characteristics and implications of their vignettes and use dilemmas for clear conceptual reasons. For example, dilemmas would seem appropriate in the context of as yet unexamined hypotheses concerning relationships involving ethical judgments that specifically focus on protagonists who seem obliged to perform 
questionable activities or face possible dire consequences. However, dilemmas are inappropriate if evaluations of purely self-interested and non-coerced protagonist behavior seem relevant because protagonists in Dilemma vignettes are behaving out of self-preservation rather than self-interest. The implicit parameters of different vignette types provide clarity of focus and can help researchers avoid the possible confounding effects of issues such as reduced protagonist freedom of choice and absence of selfinterest that are inherent in Dilemma vignettes, unless, of course, such issues are of specific interest.

In light of evidence that at least two themes may usefully be identified based on the four candidate criteria discussed, we examined other vignettes that have appeared in the published literature to determine if these criteria also enable coherent groupings to emerge. We first considered vignettes having a conspiracy theme, followed by a discussion of three additional emergent themes.

\section{Conspiracy Themed Vignettes}

A conspiracy is an agreement between at least two persons to break the law or otherwise commit an ethical violation at some point in the future. For some questionable activities, more than one willing participant is required before any behavior could be deemed inappropriate. Simply put, it often "takes two to tango", and an inducement offered by one party must be accepted by another. In bribery situations that do not involve coercion, a bribe offered must also be taken. In price fixing, multiple persons must agree on the prices to be charged for goods and services. In the transfer and sale of stolen goods, there must be both a seller and a buyer. Protagonists clearly stand to benefit from their behaviors in these instances. Offering a bribe, for example, provides something of value that might otherwise not be realized (e.g., having one’s bid accepted) and receiving a bribe obviously means getting a great deal of money. The presence of multiple willing protagonists also implies the existence of at least two ethically questionable activities (e.g., offering and accepting bribes) with neither of these clearly "more unethical" than the other. The sample of 94 students, discussed earlier, also evaluated both parties in a brief bribery vignette in which a payment of $\$ 500,000$ “could smooth the way for the company to sell” in the foreign market, with benefits accruing to both parties (Barnett, Bass, Brown and Hebert, 1998, p. 719, Vignette

2). On two items anchored by unethical (seven points) and ethical (one point), the company president 
who paid the bribe scored 4.37 and the bribe recipient scored 4.24. Shawver and Sennetti (2009, Vignette 3) reported a mean score of 3.81 on the same scale.

The published literature is replete with examples of vignettes involving multiple willing participants engaged in some form of conspiracy (see Appendix). Each of these vignettes obviously include unique details, but also have a great deal in common in that protagonists appear free to choose ethically questionable behaviors designed to create personal benefits. Survey respondents also evaluate actions that seem not to be the most ethically questionable. As discussed, multiple acts of a dubious nature are present in conspiracies with little apparent basis to conclude unambiguously and definitively that one is less appropriate than another. These vignettes also are alike in their general absence of reference to victims (e.g., companies unable or unwilling to pay bribes being excluded from consideration, auto dealers who lose money when salespeople accept kickback payments, lower tax revenues than would otherwise be realized). Conspiracy vignettes may be readily classified on the four candidate criteria identified here: 1) Protagonist Free Choice, Yes; 2) Protagonist Benefits, Yes; 3) Victim Salience, Low; 4) Has Most Questionable Action Been Evaluated, No (see Table).

As with dilemmas, there is nothing necessarily wrong with using vignettes that depict conspiracies as long as they have direct relevance to research questions asked. Some issues, however, may need to be resolved before proceeding. Is there a clear basis for asking respondents to evaluate the actions of only one vignette protagonist when there are two likely candidates from which to choose, or has one simply been selected at random or by default? What might happen to ethical judgments with a different protagonist targeted? Should respondents be asked to judge both participants in the conspiracy? Are researchers themselves able to identify potential victims that are typically ignored in such vignettes? If vignettes were written so as to make victims more salient (e.g., by specifically mentioning parties harmed by the conspiracy), what effect might that have on both the ethical judgments that emerge and the empirical support for hypotheses advanced regarding these judgments? Jones (1991) identified six situational characteristics that seem likely to affect ethical judgments, one of which was "proximity”; that is, the extent to which those affected by an action are similar to or different from the individual making 
the judgment. Although inconclusive links between ethical judgments and proximity exist (e.g., Barnett, 2001), it seems likely that if proximity could influence such judgments, then whether or not victims (that is, those affected by an action) are even mentioned at all or are omitted altogether will influence them. Future research could determine if questionable actions depicted in vignettes are viewed as less appropriate than they might otherwise be when victim salience is high rather than low.

\section{Sophie's Choice Themed Vignettes}

In the novel Sophie’s Choice (Styron, 1979), later a motion picture, the Sophie character is forced to make a harrowing choice between two equally undesirable alternatives. One of her two children is to be put to death, and Sophie must decide which child will live and which will die. In this forced decision, identical negative consequences flow from all available options. Many vignettes in the ethical judgments literature involve protagonists placed in similar, albeit less traumatic, circumstances. For example, a manager must decide which of two employees will be terminated: a relatively young employee recently hired, or an older employee "with a history of absenteeism due to illness in the family” (e.g., Cohen, Pant, and Sharp, 1998, p. 267, Vignette 5; Eweje and Brunton, 2010, p. 106, Scenario 3; Shawver and Sennetti, 2009, p. 675, Vignette 1). The Appendix presents other examples of similar vignettes.

As before, in spite of these vignettes' distinctive features, all can be classified similarly on the four parameters discussed here. In each case, protagonists are obliged to pursue a course of action in which someone will inevitably be harmed. Regardless of whether a superior officer indicates that something must be done or whether it is simply poor financial performance that dictates action, the protagonist is not making a free choice. In all likelihood, protagonists, like Sophie, would prefer not having to make such choices at all. Protagonists also do not directly benefit in any tangible way from their actions. No personal gain or rewards follow from protagonist decisions, at least in vignettes as written. Victim salience, however, is high in that specific employees, for example, are being terminated. Finally, respondents appear to be evaluating the most ethically questionable action depicted or implied in the vignette. Even superior officers who insist that protagonists must take action seem not to be behaving arbitrarily (as in the novel), but rather are themselves responding, for example, to declining financial 
revenue. Sophie's Choice vignettes manifest a coherent pattern on the four criteria addressed that differs from that found in other vignette themes: 1) Protagonist Free Choice, No; 2) Protagonist Benefits, No; 3) Victim Salience, High; 4) Has Most Questionable Action Been Evaluated, Yes (see Table).

Sophie’s Choice vignettes have the potential to advance knowledge about ethical judgments. However, investigators must be mindful both that such vignettes, in fact, have been used, and that judgments about protagonists who take actions without free choice and without coercion have direct relevance to research questions asked. Future research could consider what happens to ethical judgments if vignettes were written so as to underscore their resemblance to "Sophie’s Choice”. For example, if a manager decided to spare the jobs of the two specific employees who had been targeted in the vignette used by Valentine and Hollinsgworth (2012, see Appendix), then two different employees would have to be terminated given the apparent requirement to eliminate at least some jobs. Although this certainly is implied in the vignette as written, explicit mention could have predictable effects on overall ethical judgments. Respondents might be more inclined than they would otherwise to appreciate the difficult position in which the vignette protagonist who must terminate someone has been placed and might, as a consequence, judge this person less harshly.

\section{Runaway Trolley Themed Vignettes}

In the classic “trolley problem” (e.g., Bartels and Pizarro, 2011, p. 159; Thomson, 1985), a trolley without working brakes is bearing down on five workers on a track who have no opportunity to escape. In order to save these five lives, the driver is able to divert the trolley to a side track on which only one worker, who likewise is unable to avoid the trolley, is standing. Is it permissible to injure or kill one person in order to save several?

Some vignettes used in ethical judgments research resemble scaled down versions of this situation in which helping one person creates some harm for another. For example, an auditor with two clients discovers that one (a company on the verge of bankruptcy) owes another a considerable sum of money, and warns the creditor client of the impending bankruptcy (e.g., Buchan, 2005, Vignette 1; Cohen, Pant, and Sharp, 1993, p. 18, Vignette 2; Davis et al., 2001, p. 51, Vignette 6). The auditor was 
not required to disclose the information, did not benefit personally from this, and likely acted out of a desire to help, albeit in a small way, the creditor client by providing relevant information (that would soon be apparent anyway). This disclosure, clearly the most ethically questionable action discussed, certainly violated client confidentiality, and thus the client is a salient victim. The amount of harm created seems slight, however, as disclosure would have little to no effect on either the impending bankruptcy or the likelihood of having to repay money owed. See Appendix for other examples. Runaway Trolley vignettes generally share the following characteristics: 1) Protagonist Free Choice, Yes; 2) Protagonist Benefits, No; 3) Victim Salience, High (perhaps “low” in insider trading situations; see Appendix); 4) Has Most Questionable Action Been Evaluated, Yes (see Table).

As with other themes, investigators who use Runaway Trolley vignettes must have reason to believe that judgments in the context of this theme provide insight into specific research questions. Moreover, these vignettes must seem sensible as written and have external validity. For example, a tax advisor helped a company reduce taxable income through deceptive and questionable means (Shafer and Simmons, 2008, p. 720; see also Cruz, Shafer, and Strauser, 2000). As written, the vignette seems consistent with a Runaway Trolley theme (although with low victim salience), in that the advisor is risking sanctions or loss (or suspension) of a license to practice simply out of an apparent selfless desire to help someone else make a great deal of money. In the "real world", this seems unlikely. If the advisor performed such actions in response to a real or perceived threat on the part of the client to find a different advisor, then the vignette theme would more closely resemble Dilemma than Runaway Trolley. If this person received tangible benefits from these actions (e.g., kickbacks) then the vignette would have a Conspiracy theme. The vignette, however, was silent on threats or benefits. Therefore, its overarching theme seems ambiguous at best. Vignettes must be constructed with relevant details sufficiently delineated to allow respondents to make ethical judgments based on actual vignette content rather than assumed content involving possible threats or benefits. An absence of clarity in crucial details automatically calls into question the construct validity of the vignette and any evaluations based on it. 


\section{Whistle Blowing Themed Vignettes}

Whistle blowing occurs when one or more individuals inform the public or someone in authority about apparent dishonest, illegal, or inappropriate activities. Reactions to such informing can vary widely. Whistle blowers may sometimes be viewed as selflessly exposing wrongdoing and corruption, but may also be seen as self-aggrandizing “snitches”. Many investigators have asked for evaluations of a vignette protagonist who observes an ethically questionable activity and who must decide whether or not to inform an authority figure. For example, in the vignette used by Barnett, Bass, and Brown (1996), a student noticed another student who appeared to be cheating during an examination. Respondents evaluated the ethical appropriateness of the observer "blowing the whistle" on the cheater. See Appendix for other vignettes that featured whistle blowing.

Although these vignettes differ in many details, they all seem basically identical on the four criteria proposed here for theme identification, and differ from other types of vignettes on these same criteria. Whistle blowers are not compelled to inform others about the activities they witness, and thus have free choice to behave as they do. Protagonists also receive no tangible benefits from informing, perhaps other than an intrinsic sense of knowing that “justice has been served”. Moreover, victim salience seems low in such vignettes, in that victims have typically not been explicitly identified. For example, the student who cheated (Barnett et al., 1996) presumably was not forced into this by anyone else, and was aware that cheating carried with it a risk of repercussions if detected. Therefore, the cheater is not a "victim" of the whistle blower, other than perhaps in the narrow sense of being adversely affected by an action or circumstance. However, unlike someone whose residence was burglarized, any adverse effects followed from a free choice to engage in a risky activity. Vignettes are generally silent on mentioning any “actual victims” of activities identified by the whistle blower, such as future students who may now be subject to greater scrutiny and more mistrust because of cheating. Finally, whistle blowing is not the most ethically questionable behavior in the vignette. On two seven-point scales anchored by unethical (seven points) and ethical (one point), the sample of 94 students mentioned earlier evaluated the actions of two individuals in the peer-reporting vignette discussed above. The student who cheated scored 
6.11 and the student who reported cheating scored 2.44. With only the whistle blower evaluated, Barnett et al. (1996) reported a mean score of 5.81 out of 9 (equivalent to a score of 4.52 out of seven). ${ }^{1}$

Whistle Blowing vignettes display a coherent and unique pattern on the four criteria addressed: 1) Protagonist Free Choice, Yes; 2) Protagonist Benefits, No; 3) Victim Salience, Low; 4) Has Most Questionable Action Been Evaluated, No (see Table). Based on the preceding discussion, however, researchers may wish to ask respondents to judge the actions of both the protagonist who blows the whistle and the targeted perpetrator, and also to refer in the vignette to "actual" victims of the activity being spotlighted by the whistle blower. Such details might help make abstract vignettes "come alive” for respondents by encouraging them to consider issues of likely relevance in real situations. Whistle blowers behave as they do because they have encountered something that seems wrong to them. Survey respondents, of course, may disagree, but asking about the appropriateness of perpetrator behavior and calling attention to victims reduces the likelihood that respondents will fail to notice salient issues.

Unlike other types examined, it seems patently obvious when vignettes are relevant to whistle blowing, as evidenced by, if nothing else, the titles of papers (e.g., Chiu, 2003; Patel, 1993; Zhang, Chiu, and Wei, 2009). Nonetheless, considering the proposed criteria for theme identification suggests that this may not be as straightforward as it might seem at a glance. Not every vignette that involves blowing the whistle necessarily and unambiguously shares the same Whistle Blowing theme. Issues of potential relevance to classification in such cases may include the identity of the perpetrator and the intended beneficiary of the dubious action being considered for exposure. Barnett et al. (1994, Vignette 19) mentioned only unnamed violators of company policies, Chiu (2003) referred merely to undefined “major corruption”, and Zhang et al.’s (2009) perpetrator was described only as a “senior colleague”. Such vignettes appear not to have been written with sufficient detail to ensure that all respondents would be evaluating the same behavior in the same way because of haziness concerning both the perpetrator's identity and the underlying purpose of the questionable activities. If some judges assumed that the perpetrator happened to be the protagonist's immediate supervisor or a member of senior management, then they could conclude that the pressure to keep quiet about any apparent violations would be far 
stronger than it might if the perpetrator were a peer or an employee in a different department (or of a different organization; e.g., Ayers and Kaplan, 2005). When supervisors are involved, even respondents who believed that blowing the whistle would be the "right thing to do" might nonetheless recognize these not insignificant constraints on protagonist behavior. Such recognition, therefore, could affect not only ethical judgments but also respondent behavioral intentions (i.e., the likelihood of behaving as the protagonist did--almost all studies of ethical judgments also ask about this) in that blowing the whistle might seem inadvisable regardless of its desirability. In effect, given the personal risk to protagonists inherent in exposing their bosses, respondents who assumed "supervisor" would be evaluating a different set of circumstances with far different implications from respondents reading the same vignette but who assumed "peer”. Insufficient vignette detail produces uncertainty about the overarching theme, and raises construct validity concerns by inappropriately allowing respondents essentially to "create their own vignette” and to make their own theme decisions. After all, when free choice is reduced, as in a vignette used by Patel (1993) whose protagonist was explicitly threatened in order to maintain silence about questionable activities, then a Whistle Blowing theme has seemingly transformed into a Dilemma theme. According to the Table, Whistle Blowing and Dilemma vignettes are identical in all respects relevant to theme identification except for the issue of protagonist free choice.

Intended beneficiaries of questionable actions being considered for exposure have similar implications for theme identification. Whistle blowing intended to spotlight activities that harm organizations, such as consultant misconduct (Ayers and Kaplan, 2005), pilfering company property (Radtke, 2000) or embezzlement (Zhang et al., 2009), seems far less personally risky than does exposure of activities designed, however misguided the attempt and regardless of ultimate desirability or efficacy, to help organizations. For example, the employee of the auto parts firm who considered informing customers about quality concerns (Hansen, 1992) saved his or her employer a considerable sum of money by keeping silent. Production would probably have to be halted while conducting a time consuming and expensive investigation into quality issues, and many parts produced would likely have to be scrapped. At least in the short term, supervisors and senior managers would seem inclined, at a minimum, to resent 
an employee who blew the whistle and thus created major problems for them and their company. Management resentment, or even anger, potentially has severe negative repercussions for the career prospects or even immediate future employment of the whistle blower. In contrast, management appreciation seems likely when whistle blowers, for example, halt embezzlement, with far less threat of retaliation, and certainly with this emerging only from the embezzling colleague alone rather than the organization as a whole. If some respondents happened to recognize the dilemma in which protagonists contemplating blowing the whistle on ostensibly "helpful” activities have been placed, while others “noticed” only whistle blowing, then, again, the construct validity of the vignette and any judgments emerging from it becomes suspect. Perhaps such vignettes should specifically address likely personal implications for the protagonist who blows the whistle. Actual employees who consider exposing supervisory misconduct undoubtedly weigh personal risks carefully when making their decision. In order to enable the abstraction of a described (rather than a lived) situation conform more closely to reality, vignettes must include important details. Failure to do so again seems to encourage respondents inappropriately to "create their own vignette" and to insert details that happen to occur to them. As discussed earlier, ethical judgments should emerge from actual, rather than assumed, vignette content in order to eliminate possible threats to construct validity. Before continuing the discussion of inherent ambiguity that often seems present in vignettes, and that commenced in the context of Runaway Trolley and Whistle Blowing themes, we first address a type of vignette that has often appeared in ethical judgments research, but for which the four criteria discussed throughout may not always be relevant.

\section{Victimless Vignettes}

Some investigations into ethical judgments have used vignettes that seem curiously inappropriate in that the activities described evidently produce neither harms nor victims. For example, Chan, Wong, and Leung (2008) asked respondents to evaluate the ethical appropriateness of people bringing their own

shopping bags to stores. Is it ethical for people to apply for credit cards that they rarely use (Ding, Chang, and Liu, 2009), for a store to refund money to customers (Dornoff and Tankersley, 1975), for a bank to extend credit or loans that violate only its “normal (internal) lending criteria” (e.g., Cohen et al., 1998, 
Vignette 2; Shawver and Sennetti, 2009), for a business to "buy ergonomically designed tools to avoid muscle injuries” (Bucar, Glas, and Hisrich, 2003, p. 277), or for managers of a Mexican restaurant to hire Hispanic employees (Schepers, 2003)? Such vignettes do not easily fit the criteria for theme identification in that both "Victim Salience” and "Has Most Questionable Action Been Evaluated” are not applicable in vignettes that feature neither victims nor questionable actions. Perhaps more importantly, if the goal of such research is to advance knowledge about ethical judgments, the point of such vignettes is not readily apparent.

\section{Rollfast Bicycle Company: Theme Ambiguity}

A vivid example of theme ambiguity has appeared in the context of the "Rollfast Bicycle Company” vignette used in several investigations. The basic plot is that, although Rollfast was barred from selling bicycles in an Asian country, a large cash payment would enable access to the market and thus substantial profits. Without explanation or even acknowledgement, many vignette details differed across studies. Some examples are: 1) the presence or absence of severe time constraints, highly salient in Cherry (2006) but not mentioned in Barnett et al. (1998); 2) the specific amount of the bribe, not provided in Cherry and Fraedrich (2002) but appearing in Barnett et al. (1998; that is, half a million dollars); 3) the expected benefit to Rollfast from bribery, whether not mentioned (Cherry, 2006), five million dollars (Barnett et al., 1998), or five dollars (Barnett et al., 1994, p. 478, Vignette 8; likely a typographical error); and 4) precisely whose money was being spent, that is, the company's money or the

employee’s own money (Cherry, Lee, and Chien, 2003, p. 373). ${ }^{2}$ Other details that varied across different studies, however, potentially shift the overarching vignette theme. On the surface, the case seems to describe a conspiracy. However, the identity of the vignette protagonist, whether company president (Barnett et al., 1994, 1998) or an employee with an unspecified job title but who seems not to be a member of senior management (Cherry, 2006; Cherry and Fraedrich, 2002; Cherry et al., 2003), may matter greatly to the ethical judgments that emerge because this detail blurs the line between Conspiracy and Dilemma themes. A protagonist who was "merely" an employee may feel compelled to pay the bribe money simply given the existence of a superior who likely would react favorably to increased profits and 
who might dismiss an employee who passed up an opportunity for these. This compulsion, however, seems muted or even entirely absent when a company president is asked to pay a bribe, because a chief executive officer would have ample opportunity to explain, for example, to the board of directors that this profitable opportunity was declined on ethical grounds. As discussed earlier in the context of Dilemma vignettes, if the ethical judgments provided by even some survey respondents could be influenced by reduced protagonist “degrees of freedom”, then the construct validity of vignettes and the judgments that emerge from them seem suspect because not all respondents would necessarily have evaluated the activities presented using the same criteria. Again, vignettes details require sufficient clarity to permit ethical judgments to be based on actual rather than assumed content.

One commonality across different versions of the Rollfast situation, whether framed as dilemma or conspiracy, was the absence of any references to victims of bribery. This shared characteristic is unsurprising because, after all, victim salience is low in both vignette types (see Table). Victims of bribery might include customers and shareholders required ultimately to shoulder the costs associated with bribes, other companies excluded from consideration if they are unable or unwilling to bribe, and even bribing companies themselves who may now have little choice but to acquiesce to any demands for additional payments (cf. Carroll and Buchholtz, 2012, p. 319). As discussed previously, respondent ethical judgments may also be affected by victim salience in that bribery (also informing others about opportunities for insider trading, relevant to a Runaway Trolley theme; see Appendix) would likely be regarded generally as less appropriate than it might otherwise be when victims have been identified.

\section{Some Implications of Vignette Theme Identification}

Ultimately, the potential for vignette theme identification to contribute meaningfully to the advancement of knowledge about ethical judgments is a matter for future investigation. In the meantime, however, evidence already suggests that viewing relevant research through the lens of vignette themes helps both to determine whether or not to aggregate data emerging from multiple vignettes, and also to make sense of patterns of unexpectedly weak or seemingly contradictory findings that, until now, have defied easy understanding. 


\section{Aggregated or Disaggregated Data}

One issue that inevitably arises whenever researchers use more than one vignette is whether scores from different vignettes should be aggregated to create an overall ethical judgments score or should be considered separately. Little firm guidance is available in the literature. McMahon and Harvey (2007) recommended aggregation as a general rule, but many studies have not followed this advice (e.g., Barnett et al., 1994; Valentine and Hollingsworth, 2012). Separate analyses for each vignette seem not to be excessive, perhaps, when two vignettes are used, but certainly have the potential to consume valuable journal space when analyses relevant to three (Davis et al., 2001, Tables 4, 7, and 8; Vitell, Bakir, Paolillo, Hidalgo, Al-Khatib and Rawwas, 2003, Tables 2-9), six (Cohen et al., 1993, Tables 4-7), or twenty-six separate vignettes are presented (Barnett et al, 1994, Tables 1, 3, and 4). The apparent existence of distinct themes, however, suggests a straightforward resolution to the issue of aggregation appropriateness. Ethical judgments emerging from different vignettes with the same theme appear to represent the same underlying construct, and aggregated scores would not only be parsimonious and able to be presented succinctly, but also conceptually meaningful. However, scores from vignettes using different themes (e.g., Conspiracy and Sophie’s Choice) likely should not be aggregated because of the ambiguous construct validity of the resulting measure. An ethical judgment about a situation in which two parties plan a questionable act for mutual benefit is simply not automatically and necessarily equivalent to a judgment about a situation in which managers are compelled by circumstances beyond their control to terminate some employees.

The consequences of inappropriate aggregation may be profound. Consider the meta-analysis of Pan and Sparks (2012) that, for example, amalgamated findings relevant to ethical idealism and relativism from the 26 vignettes of Barnett et al. (1994) and the peer-blowing vignette of Barnett et al. (1996). Such procedures imply that judgments about the ethicality of a student reporting apparent cheating (Barnett et al., 1996; Whistle Blowing), someone who stole a life-saving drug (Barnett et al., 1994, Vignette 2; Runaway Trolley), an auditor ordered to destroy papers (Vignette 3; Dilemma), a company that polluted the air when this would likely not be detected (Vignette 10; Classic), a worker that took longer than 
necessary to do a job (Vignette 15; benefits to worker not specified), and a salesperson that offered gifts to customers (Vignette 25; harms and victims not specified) were essentially equivalent and thus able to be combined meaningfully. Until empirical evidence to the contrary is provided, apparent inappropriate aggregation of results across multiple vignettes with different themes raises construct validity concerns that call into question the ultimate value of the meta-analytic results reported by Pan and Sparks (2012).

\section{A Thematic Recasting of Existing Findings}

Two personality traits generally associated with “poor ethics” are Machiavellianism (high) and locus of control (external). Such results, however, have not appeared consistently in ethical judgments research in spite of hypotheses suggesting otherwise (Mudrack and Mason, 2012). Machiavellianism is characterized by intense self-focus and a willingness to do almost anything that serves one's own interests (Christie and Geis, 1970), and externally controlled individuals, who largely feel unable to get what they want through their own direct efforts and abilities, may be inclined to resort to ethically questionable tactics (e.g., Mudrack, 1990). Therefore, both Machiavellianism and locus of control seem likely to assume particular relevance for ethical judgments in situations in which vignette protagonists act in order to benefit themselves personally and to advance their own interests; that is, in Classic and Conspiracy situations according to the Table. Indeed, Mudrack, Bloodgood, and Turnley (2012) indicated that Machiavellianism related as expected to ethical judgments in three Classic themed vignettes. Shafer and Simmons (2008, p. 720) also reported modest connections with Machiavellianism in two vignettes of indeterminate theme discussed earlier, but that possibly depicted conspiracies. Empirical support for relationships with Machiavellianism would likely have been stronger had Conspiracy vignettes been constructed that highlighted personal benefits accruing, for example, to the tax advisor from the questionable behaviors described.

In contrast, no vignette used in research reporting unexpected trivial connections between ethical judgments and Machiavellianism and/or locus of control mentioned how protagonists might personally benefit from actions, not all of which seemed ethically questionable. Schepers' (2003, p.343) vignette discussed hiring “young attractive Hispanics” for a chain of Mexican themed restaurants in order to 
increase sales that more definitively benefit the company rather than the protagonist. Bass, Barnett, and Brown’s (1999, p. 192) vignette simply involved "liking for one customer and disliking for another" affecting "price, delivery, and other decisions regarding the terms of sale”, and was silent on any direct implications for protagonists. Loaning "software to another person for use on that person's computer" (McMahon and Cohen, 2009, pp. 15-16; see also Eweje and Brunton, 2010, Scenario 8; Jung, 2009; Radtke, 2000, Vignette 4; Wagner and Sanders, 2001, p. 164) suggests a desire to assist the borrower, and thus a Runaway Trolley theme, but helping others has little relevance for Machiavellians, at least in the absence of a quid pro quo. Razzaque and Hwee (2002) alluded to, but did not provide, a vignette that apparently featured a purchasing manager violating company rules by going to lunch with a specific person. Implications for the purchasing manager, beyond having a lunch companion, were not discussed. One of the credit card vignettes of Ding et al. (2009, p. 833) involved someone continuing to use their card even though they had not yet received a bill. In each of these studies, results that provided weak or no hypothesis support now seem unsurprising given the absence of any tangible protagonist benefit. Investigators interested in empirical support for hypotheses involving ethical judgments need to ensure that salient vignette details have conceptual relevance to the construct linked to such judgments.

\section{DISCUSSION}

The ethical judgments literature is characterized by remarkable diversity in the stimulus materials presented to potential survey respondents, and the general absence of both apparent rationales for choices made regarding such materials, and often the materials themselves. Perhaps none of this would seem especially relevant if knowledge about ethical judgments had accumulated and advanced in the last quarter century, but this seems not to have been the case (cf. Mudrack and Mason, 2012). Rather than adding to research findings and understanding of ethical judgments, vignette diversity has seemingly led to an inchoate and rather fragmented body of questionable work. A greater emphasis on overarching themes embedded in vignettes, and more careful vignette construction to eliminate ambiguities, seem urgently required as a forward research direction. 
The purpose of this paper was not to classify and categorize any and all possible vignettes that have been, or could be, used in ethical judgments research, but rather to examine carefully some vignettes that have appeared in the literature in an effort to determine what they might have in common. Building on earlier research, we proposed four criteria on which vignettes might meaningfully be categorized: 1) is the protagonist able to make a free choice whether or not to engage in the activity described; 2) does the protagonist benefit personally from this activity; 3) how salient are victims in the vignette description; and 4) have respondents been asked to evaluate the appropriateness of the most questionable activity described or implicit in the vignette. We identified six overarching vignette themes, labeled here as Dilemma, Classic, Conspiracy, Sophie’s Choice, Runaway Trolley, and Whistle Blowing (see Table), based on unique patterns of responses to the questions implicit in these criteria. Moreover, preliminary evidence suggests that the parameters used to delineate different themes matter to at least some survey respondents and influence their evaluations, and that the likelihood of finding empirical support for hypotheses advanced involving ethical judgments may be affected by the vignette theme selected.

Although vignettes used in the literature have tended to conform to specific patterns, this does not necessarily imply that such patterns are always normatively appropriate. Vignettes with low victim salience, for example, may require alteration to increase this in order to make otherwise abstract vignette details “come alive” and thus more closely approximate actual situations for respondents who may not always have carefully thought through the full implications of the situation in which protagonists have been placed. High Machiavellian individuals, for example, may not care much about victims regardless of their salience, but actually discussing victims at least increases the likelihood that they will be considered rather than overlooked completely.

Moreover, the six themes identified are probably not the only ones that might be meaningful given that two responses on each of four criteria yield sixteen possible combinations. Future study is required to determine which of these additional combinations may be theoretically interesting (e.g., whistle blowing protagonists who benefit by exposing apparent malfeasance; for instance, by attempting to eliminate a rival for a promotional opportunity), and whether criteria such as intended beneficiaries of 
activities evaluated might be relevant for theme identification. For example, Classic vignettes in which organizations profit from questionable activities (e.g., Reidenbach and Robin, 1990) may actually represent a theme that differs from vignettes in which organizations are harmed by such practices (Barnett and Valentine, 2004; Hudson and Miller, 2005; see also Runaway Trolley vignettes with differing levels of victim salience), or perhaps these are best conceived simply as variations on a single theme.

Although this paper has likely not finalized the process of theme identification, the six themes addressed here provide a parsimonious starting point from which to overcome the limitations of much prior ethical judgments research. As discussed throughout, given that reasons for using specific vignettes rarely appeared in the literature, no evidence exists to suggest that researchers were necessarily always aware of the essential characteristics of vignettes used, or possible implications of these characteristics for emergent ethical judgments or hypothesis support. Many vignettes used in the literature have uncertain construct validity if the purpose of research was to elicit respondent impressions of self-interested ethically questionable behaviors, because these are absent in Dilemma, Sophie's Choice, and Runaway Trolley vignettes. In such instances, if some (but not all) respondents clearly perceived, for example, the implicit dilemma or choice that almost seem to be "hiding in plain sight", then not all respondents would have evaluated the same vignette in the same way. Under such circumstances, construct validity concerns create heretofore unconsidered plausible rival explanations for results, typically the absence of significant results (cf. Mudrack and Mason, 2012). A specific proposition that perhaps may guide future research is that if the appropriateness of self-interested protagonist behavior is to be investigated, then vignettes presented to respondents must feature self-interested protagonist behavior.

In general, it seems entirely inappropriate for respondents to be asked to furnish their own interpretations of vignettes whose details or themes are ambiguous. In the vignette used by Shafer and Simmons (2008), for instance, respondents themselves implicitly seem to have been asked to "fill in the blanks” and decide whether the situation was consistent with a Dilemma, a Conspiracy, or a Runaway Trolley theme. Researchers need to avoid possible ambiguities in constructing vignettes, determine in advance what type of vignette is needed to provide insight into specific research questions, and assess the 
requirement for additional details, such as references to victims. However, as yet unexplored research directions in which vignette ambiguity is deliberate may be interesting and worthwhile. For example, what respondent characteristics might be associated with noticing crucial vignette details that apparently elude many observers, whether survey respondents or researchers?

Ethical judgments are not possible in the absence of something to judge. To the best of our knowledge, however, this is the first time that the content of such judgments has been taken seriously, explicitly reflected upon, and examined in any depth. If the purpose of ethical judgments research is "the explanation, prediction, and control of unethical behavior” (Flory, Phillips, Reidenbach, and Robin, 1993, p. 418), then it may be that the journey toward this worthwhile objective, although long delayed, may now begin in earnest. 


\section{Notes}

${ }^{1}$ Barnett et al. (1996) used a nine-point semantic differential scale for respondents to record their reactions to the observer informing the professor about the apparent cheating. Ethical judgments were assessed with the eight items from the Multidimensional Ethics Scale (Reidenbach and Robin, 1990). The left anchor descriptor included, for example, the labels fair and just, while the corresponding right anchor labels were unfair and unjust (p. 1171). Although the paper did not address the precise meaning of higher or lower ethical judgments scores, higher scores on these two items, and four others, thus suggested that respondents interpreted the reporting as ethically inappropriate (i.e., this was unfair). However, for two of the eight items, the right anchor descriptors were does not violate an unwritten contract and does not violate an unspoken promise which implies viewing the activity as ethically appropriate. The matching left anchors involved violations of unwritten contracts and unspoken promises, which correspond with regarding the action as unfair and unjust. The paper, however, did not specify whether any alterations were made to the scoring protocol on the "unspoken promise" and "unwritten contract” items. Scores on the eight items are not interpretable if these were simply combined or averaged without reversing the scoring on these two. See Mudrack and Mason (2012, Appendix) for additional discussion about ambiguities in many published reports concerning the precise meaning and implications of high (or low) scores on ethical judgments measures and the obvious need for clarity here.

${ }^{2}$ The vignette used by Cherry et al. (2003) appears to lack “real world” validity. In an actual bribery situation, bribe recipients would obviously be unaware of how much money Barnett et al.'s (1998) protagonists would be willing to pay $(\$ 500,000)$. However, access to a large market is potentially highly lucrative, and a considerable sum of money would have to change hands for such access realistically to be attained. How likely is it that employee protagonists would even have such funds at their disposal or believe that any possible personal rewards arising from closing this deal (e.g., bonuses, promotions) would exceed the amount of money that definitely would have to be spent? Bribe recipients seem unlikely to be swayed by relatively small sums of money (e.g., fifty, five hundred, or even five thousand dollars or Euros) that employees might be able to raise from personal funds, and employees would seem 
unable or unwilling to furnish larger sums. Respondent ethical judgments in the context of this vignette may have been influenced by the improbability of the situation. 


\section{References}

Ayers, S. and S. E. Kaplan: 2005, 'Wrongdoing by Consultants: An Examination of Employees’

Reporting Intentions', Journal of Business Ethics 57, 121-137.

Bailey, W. and A. Spicer: 2007, 'When Does National Identity Matter? Convergence and Divergence in International Business Ethics’, Academy of Management Journal 50, 1462-1480.

Barnett, T.: 2001, 'Dimensions of Moral Intensity and Ethical Decision Making: An Empirical Study’, Journal of Applied Social Psychology 31, 1038-1057.

Barnett, T., K. Bass and G. Brown: 1994, ‘Ethical Ideology and Ethical Judgment Regarding Ethical Issues in Business', Journal of Business Ethics 13, 469-480.

Barnett, T., K. Bass and G. Brown: 1996, ‘Religiosity, Ethical Ideology, and Intentions to Report a Peer’s Wrongdoing', Journal of Business Ethics 15, 1161-1174.

Barnett, T., K. Bass, G. Brown and F. J. Hebert: 1998, 'Ethical Ideology and the Ethical Judgments of Marketing Professionals', Journal of Business Ethics 17, 715-723.

Barnett, T. and S. Valentine: 2004, ‘Issue Contingencies and Marketers’ Recognition of Ethical Issues, Ethical Judgments and Behavioral Intentions’, Journal of Business Research 57, 338-346.

Bartels, D. M. and D. A. Pizarro: 2011, ‘The Mismeasure of Morals: Antisocial Personality Traits Predict Utilitarian Responses to Moral Dilemmas’, Cognition 121, 154-161.

Bass, K., T. Barnett and G. Brown: 1999, ‘Individual Difference Variables, Ethical Judgments, and Ethical Behavioral Intentions', Business Ethics Quarterly 9, 183-205.

Buchan, H. F.: 2005, 'Ethical Decision Making in the Public Accounting Profession: An Extension of Ajzen’s Theory of Planned Behavior', Journal of Business Ethics 61, 165-181.

Bucar, B., M. Glas and R. D. Hisrich: 2003, ‘Ethics and Entrepreneurs: An International Comparative Study’, Journal of Business Venturing 18, 261-281.

Carroll, A. B. and A. K. Buchholtz: 2012, Business and Society: Ethics, Sustainability, and Stakeholder Management, 8th edition (South-Western, Mason, OH). 
Chan, R. Y. K., Y. H. Wong and T. K. P. Leung: 2008, 'Applying Ethical Concepts to the Study of “Green” Consumer Behavior: An Analysis of Chinese Consumers’ Intentions to Bring their Own Shopping Bags', Journal of Business Ethics 79, 469-481.

Cherry, J.: 2006, ‘The Impact of Normative Influence and Locus of Control on Ethical Judgments and Intentions: A Cross-Cultural Comparison', Journal of Business Ethics 68, 113-132.

Cherry, J. and J. Fraedrich: 2002, 'Perceived Risk, Moral Philosophy and Marketing Ethics: Mediating Influences on Sales Managers’ Ethical Decision-Making’, Journal of Business Research 55, 951-962. Cherry, J., M. Lee and C. S. Chien: 2003, ‘A Cross-Cultural Application of a Theoretical Model of Business Ethics: Bridging the Gap between Theory and Data’, Journal of Business Ethics 44, 359-376. Chiu, R. K.: 2003, 'Ethical Judgment and Whistleblowing Intention: Examining the Moderating Role of Locus of Control', Journal of Business Ethics 43, 65-74.

Chiu, R. K. and C. B. Erdener: 2003, 'The Ethics of Peer Reporting in Chinese Societies: Evidence from Hong Kong and Shanghai’, International Journal of Human Resource Management 14, 335-353.

Christie, R. and F. L. Geis: 1970, Studies in Machiavellianism, (Academic Press, New York).

Cohen, J. R. and N. M. Bennie: 2006, ‘The Applicability of a Contingent Factors Model to Accounting Ethics Research', Journal of Business Ethics 68, 1-18.

Cohen, J., L. Pant and D. Sharp: 1993, ‘A Validation and Extension of a Multidimensional Ethics Scale’, Journal of Business Ethics 12, 13-26.

Cohen, J. R., L. W. Pant and D. J. Sharp: 1998, ‘The Effect of Gender and Academic Discipline Diversity on the Ethical Evaluations, Ethical Intentions and Ethical Orientation of Potential Public Accounting Recruits', Accounting Horizons 12, 250-270.

Collins, D.: 2000, 'The Quest to Improve the Human Condition: The First 1500 Articles Published in Journal of Business Ethics', Journal of Business Ethics 26, 1-73.

Cruz, C. A., W. E. Shafer and J. R. Strauser: 2000, 'A Multidimensional Analysis of Tax Practitioners' Ethical Judgments', Journal of Business Ethics 24, 223-244.

Davis, M. A., M. G. Andersen and M. B. Curtis: 2001, 'Measuring Ethical Ideology in Business Ethics: A 
Critical Analysis of the Ethics Position Questionnaire', Journal of Business Ethics 32, 35-53.

Ding, C. G., K. Chang and N. T. Liu: 2009, ‘The Roles of Personality and General Ethical Judgments in Intention to Not Repay Credit Card Expenses’, Service Industries Journal 29, 813-834.

Dornoff, R. J. and C. B. Tankersley: 1975, 'Perceptual Differences in Market Transactions: A Source of Consumer Frustration', Journal of Consumer Affairs 97, 97-103.

Eweje, G., and M. Brunton: 2010, ‘Ethical Perceptions of Business Students in a New Zealand University: Do Gender, Age, and Work Experience Matter?', Business Ethics: A European Review 19, 95-111.

Fleischman, G. and S. Valentine: 2003, 'Professionals’ Tax Liability Assessments and Ethical Evaluations in an Equitable Relief Innocent Spouse Case’, Journal of Business Ethics 42, 27-44.

Flory, S. M., T. J. Phillips, Jr., R. E. Reidenbach and D. P. Robin: 1992, 'A Multidimensional Analysis of Selected Ethical Issues in Accounting', Accounting Review 67, 284-302.

Flory, S. M., T. J. Phillips, Jr., R. E. Reidenbach and D. P. Robin: 1993, ‘A Reply to “A Comment on a Multidimensional Analysis of Selected Ethical Issues in Accounting'”, Accounting Review 68, 417-421. Ge, L., \& S. Thomas: 2008). 'A cross-cultural comparison of the deliberative reasoning of Canadian and Chinese accounting students', Journal of Business Ethics 82, 189-211.

Hansen, R. S.: 1992, ‘A Multidimensional Scale for Measuring Business Ethics: A Purification and a Refinement', Journal of Business Ethics 11, 523-534.

Hudson, S. and G. Miller: 2005, ‘Ethical Orientation and Awareness of Tourism Students’, Journal of Business Ethics 62, 383-396.

Jones, T. M.: 1991, ‘Ethical Decision Making by Individuals in Organizations: An Issue-Contingent Model', Academy of Management Review 16, 366-395.

Jung, I.: 2009, ‘Ethical Judgments and Behaviors: Applying a Multidimensional Ethics Scale to Measuring ICT Ethics of College Students', Computers and Education 53, 940-949.

Kujala, J.: 2001, ‘A Multidimensional Approach to Finnish Managers’ Moral Decision-Making’, Journal of Business Ethics 34, 231-254. 
Landeros, R. and R. E. Plank: 1996, 'How Ethical are Purchasing Management Professionals?’, Journal of Business Ethics 15, 789-803.

Loo, R.: 2002, ‘Tackling Ethical Dilemmas in Project Management Using Vignettes’, International Journal of Project Management 20, 489-495.

Marques, P. A. and J. Azevedo-Pereira: 2009, 'Ethical Ideology and Ethical Judgments in the Portugese Accounting Profession', Journal of Business Ethics 86, 227-242.

McMahon, J. M. and R. Cohen: 2009, 'Lost in Cyberspace: Ethical Decision Making in the Online Environment', Ethics and Information Technology 11, 1-17.

McMahon, J. M. and R. J. Harvey: 2006, ‘An Analysis of the Factor Structure of Jones’ Moral Intensity Construct', Journal of Business Ethics 64, 381-404.

McMahon, J. M. and R. J. Harvey: 2007, 'Psychometric Properties of the Reidenbach-Robin Multidimensional Ethics Scale’, Journal of Business Ethics 72, 27-39.

Mudrack, P. E.: 1990, ‘Machiavellianism and Locus of Control: A Meta-Analytic Review’, Journal of Social Psychology 130, 125-126.

Mudrack, P. E., J. M. Bloodgood and W. H. Turnley: 2012, ‘Some Ethical Implications of Individual Competitiveness', Journal of Business Ethics 108, 347-359.

Mudrack, P. E. and E. S. Mason: 2012, ‘Ethical Judgments: What Do We Know, Where Do We Go?’, Journal of Business Ethics, DOI 10.1007/s10551-012-1426-z.

Pan, Y. and J. R. Sparks: 2012, 'Predictors, Consequence, and Measurement of Ethical Judgments:

Review and Meta-Analysis', Journal of Business Research 65, 84-91.

Patel, C.: 2003, ‘Some Cross-Cultural Evidence on Whistle-Blowing as an Internal Control Mechanism’, Journal of International Accounting Research 2, 69-96.

Radtke, R. R.: 2000, 'The Effects of Gender and Setting on Accountants’ Ethically Sensitive Situations', Journal of Business Ethics 24, 299-312.

Razzaque, M. A. and T. P. Hwee: 2002, 'Ethics and Purchasing Dilemma: A Singaporean View’, Journal of Business Ethics 35, 307-326. 
Reidenbach, R. E. and D. P. Robin: 1990, 'Toward the Development of a Multidimensional Scale for Improving Evaluations of Business Ethics’, Journal of Business Ethics 9, 639-653.

Reidenbach, R. E., D. P. Robin and L. Dawson: 1991, ‘An Application and Extension of a Multidimensional Ethics Scale to Selected Marketing Practices and Marketing Groups', Journal of the Academy of Marketing Science 19, 83-92.

Robin, D. P., R. E. Reidenbach and B. J. Babin: 1997, ‘The Nature, Measurement, and Stability of Ethical Judgments in the Workplace', Psychological Reports 80, 563-580.

Schepers, D. H.: 2003, 'Machiavellianism, Profit, and the Dimensions of Ethical Judgment: A Study of Impact', Journal of Business Ethics 42, 339-352.

Schwepker, C. H., Jr., and T. N. Ingram: 1996, ‘Improving Sales Performance through Ethics: The Relationship between Salesperson Moral Judgment and Job Performance’, Journal of Business Ethics 15, $1151-1160$.

Shafer, W. E.: 2002, 'Effects of Materiality, Risk, and Ethical Perceptions on Fraudulent Reporting by Financial Executives’, Journal of Business Ethics 38, 243-262.

Shafer, W. E.: 2008, ‘Ethical Climate in Chinese CPA Firms’, Accounting, Organizations and Society 33, 825-835.

Shafer, W. E. and Simmons, R. S.: 2008, 'Social Responsibility, Machiavellianism and Tax Avoidance', Accounting, Auditing and Accountability Journal 21, 695-720.

Shawver, T. J. and J. T. Sennetti: 2009, 'Measuring Ethical Sensitivity and Evaluation', Journal of Business Ethics 88, 663-678.

Smith, N. C., S. S. Simpson and C. Y. Huang: 2007, 'Why Managers Fail to Do the Right Thing: An Empirical Study of Unethical and Illegal Conduct', Business Ethics Quarterly 17, 633-667.

Sparks, J. R. and Y. Pan: 2010, 'Ethical Judgments in Business Ethics Research: Definition, and Research Agenda', Journal of Business Ethics 91, 405-418. 
Stevenson, T. H. and C. D. Bodkin: 1998, ‘A Cross-National Comparison of University Students’

Perceptions Regarding the Ethics and Acceptability of Sales Practices’, Journal of Business Ethics 17, 4555.

Styron, W.: 1979, Sophie’s Choice, (Random House: New York).

Thomson, J. J.: 1985, ‘The Trolley Problem’, Yale Law Journal 94 (6), 1395-1415.

Tsalikis, J. and M. S. LaTour: 1995, 'Bribery and Extortion in International Business: Ethical Perceptions of Greeks Compared to Americans’, Journal of Business Ethics 14, 249-264.

Tsalikis, J. and O. Nwachukwu: 1991, 'A Comparison of Nigerian to American Views of Bribery and Extortion in International Commerce', Journal of Business Ethics 10, 85-98.

Valentine, S. R. and C. R. Bateman: 2011, ‘The Impact of Ethical Ideologies, Moral Intensity, and Social Context on Sales-Based Ethical Reasoning', Journal of Business Ethics 102, 155-168.

Valentine, S. and D. Hollingsworth: 2012, 'Moral Intensity, Issue Importance, and Ethical reasoning in Operations Situations', Journal of Business Ethics 18, 509-523.

Valentine, S. R. and T. L. Rittenburg: 2004, 'Spanish and American Professionals’ Ethical Evaluations in Global Situations’, Journal of Business Ethics 51, 1-13.

Valentine, S. R. and T. L. Rittenburg: 2007, ‘The Ethical Decision Making of Men and Women Executives in International Business Situations’, Journal of Business Ethics 71, 125-134.

Vitell, S. J., A. Bakir, J. G. P. Paolillo, E. R. Hidalgo, J. Al-Khatib and M. Y. A. Rawwas: 2003, 'Ethical Judgments and Intentions: A Multinational Study of Marketing Professionals’, Business Ethics: A European Review 12, 151-171.

Vitell, S. J. and A. Patwardhan: 2008, ‘The Role of Moral Intensity and Moral Philosophy in Ethical Decision-Making: A Cross-Cultural Comparison of China and the European Union', Business Ethics: A European Review 17, 196-209.

Wagner, S. C. and G. L. Sanders: 2001, 'Considerations in Ethical Decision-Making and Software Piracy', Journal of Business Ethics 29, 161-167. 
Zhang, J., R. Chiu and L. Wei: 2009, 'Decision-Making Process of Internal Whistleblowing Behavior in China: Empirical Evidence and Implications’, Journal of Business Ethics 88, 25-41. 


\title{
Table
}

\section{The Underlying Composition of Six Vignette Themes}

\author{
Vignette Type
}

Sophie's Runaway Whistle

Vignette Criteria

Dilemma

Classic

Conspiracy

Choice

Trolley

Blowing

1) Protagonist Free Choice

No

Yes

Yes

No

Yes

Yes

2) Protagonist Benefits

No

Yes

Yes

No

No

No

3) Victim Salience

Low

High

Low

High

High

Low

4) Most Questionable

No

Yes

No

Yes

Yes

No 


\section{Appendix}

\section{Examples of Vignettes and their Corresponding Themes}

\section{Dilemma}

Cohen, Pant, and Sharp (1998, Vignette 4; see also Eweje and Brunton, 2010, Scenario 6; Shawver and Sennetti, 2009): A CEO asked a controller to reduce an estimate for bad debts. From the controller's point of view, such "requests" may be difficult to distinguish from direct orders.

Cruz, Shafer, and Strauser (2000): a tax professional complied with questionable client tax requests. Without such compliance, clients may look elsewhere.

Flory, Phillips, Reidenbach, and Robin (1992, p. 299, Scenario A): Unless an accountant does what his boss says, the accountant's "position in the company would be in jeopardy".

Ge and Thomas (2008, p. 206; see also Radtke, 2000, p. 310, Vignette 14): Managers ordered subordinates to modify negative comments in a letter to a client. Refusing direct orders may be grounds for dismissal.

Loo (2002, p. 495): A company vice president suggested that a project manager comply with a “demand for a kick back” payment of "several thousand dollars”. "Suggestions” from a vice president seem difficult to ignore.

Marques and Azevedo-Pereira (2009): an accountant was pressured by a board member (Vignette 1) and a client (Vignette 5).

Patel (1993): protagonists elected not to blow the whistle on questionable expenses and invoices in the face of implicit (Vignette 1) and explicit (Vignette 2) threats.

Smith, Simpson, and Huang (2007): Managers ordered subordinates to engage in bribery and price-fixing. Again, refusing direct orders seems personally risky.

Tsalikis and LaTour (1995, p. 253; Tsalikis and Nwachukwu, 1991, p. 88): Government officials demanded bribe money for help in obtaining valuable government contracts. 
Valentine and Bateman (2011, p. 160): A buyer for a department store demanded "a valuable present” in order "to maintain good relations” with the protagonist's company that supplies the store with clothing.

\section{Classic}

Bailey and Spicer (2007, p. 1469): a company that failed to inform employees exposed to hazardous chemicals about the associated health risks benefitted by having a compliant work force.

Barnett and Valentine (2004, p. 341): a salesperson booked expensive business flights with an airline in order to earn frequent flier points for personal use.

Buchan (2005, p. 179, Vignette 3): a partner in an accounting firm lied to prospective clients who ask whether audit fees are likely to rise in the future.

Hudson and Miller (2005, p. 394, Scenario 6): when customers pay cash, two tour representatives kept some of the money for themselves.

Reidenbach and Robin (1990): an overeager salesperson withheld important information from potential customers apparently without supervisory knowledge or approval.

Reidenbach and Robin (1990): a grocery store located in a poor neighborhood raised prices on the day that customers received welfare checks and were thus likely to shop.

\section{Conspiracy}

Dornoff and Tankersley (1975, Vignettes 4 and 8): although protagonists never actually met, a retailer attempted to increase sales by using questionable advertising displays created by an outside agency.

Kujala (2001, p. 233): by making a payment to the customer’s Swiss bank account, a “company will receive a big order from abroad”. Another vignette involved a qualified job applicant suggesting to the CEO that he be paid "without paying taxes” (p. 233). The CEO accepted this proposal because it would save the company a great deal of money, and the candidate benefitted by having a job.

McMahon and Harvey (2006, p. 387): a company seeking to expand in a foreign market made a 
“contribution to the ruling political party” to gain access (see also Valentine and Rittenburg, 2004, p. 10, Scenario 7; Valentine and Rittenburg, 2007).

Reidenbach, Robin, and Dawson (1991, p. 85): an auto salesperson accepted \$100 from a customer in order to have the overall vehicle price reduced by $\$ 300$.

Tsalikis and Nwachukwu (1991, p. 87): money was provided to government officials in exchange for assistance in obtaining lucrative contracts (see also Tsalikis and LaTour, 1995, p. 252; Vitell and Patwardhan, 2008, pp. 207-208).

Valentine and Rittenburg (2004, p. 9, Scenario 1): a Korean firm paid an employee of an American auto parts manufacturer for confidential and proprietary product information.

\section{Sophie's Choice}

McMahon and Harvey (2006, p. 390; see also Davis, Andersen, and Curtis, 2001, p. 50, Vignette 1): In order to reduce overhead expenses, a manager who must choose among three recommendations that all will harm employees, elected to cut retirement benefits.

McMahon and Harvey (2006, p. 392): Managers obligated to reduce expenses targeted five employees (out of at least 100) for salary reduction of $\$ 8000$ each.

Valentine and Hollingsworth (2012, p. 514, Vignette 1): A manager who must improve operational efficiency chose two otherwise high performing subordinates out of many likely candidates to be laid off.

\section{Runaway Trolley}

Bailey and Spicer (2007, p. 1469): Even though a firm was losing money, it did not close a factory that would have thrown many employees out of work.

Bucar, Glas, and Hisrich (2003, p. 277): A protagonist who concealed a “supervisor’s wrong expense report” presumably helps the supervisor by harming the organization.

Cohen, Pant, and Sharp (1993, p. 18, Vignette 4): In order to facilitate negotiations between two accounting firms contemplating a merger, one negotiator asks another for copies of the work papers of clients who are unaware of the merger. Providing these papers would violate client confidentiality. 
Hudson and Miller (2005, p. 394, Scenario 5): In order to accommodate tourists, an airline "begins a limited number of Sunday flights" to an island during the main tourist season even though some local residents are opposed to such flights.

Landeros and Plank (1996, p. 793): A buyer provided a salesperson inside information on a recently concluded bidding situation in exchange for a charitable donation.

Marques and Azevedo-Pereira (2009, p. 240, Scenario II; see also Radtke, 2000, Vignettes 5 and 6): An accountant who was aware of positive financial results at a company, not yet disclosed to shareholders, advised a friend to purchase shares in this company.

Radtke (2000, p. 309, Vignette 7): One friend of the vignette protagonist is selling a used car to another friend and represented it as "never having been in an accident”. The protagonist, however, is aware of such an accident that caused "substantial damage” that was subsequently repaired, and wonders whether or not to inform the buyer of the true state of affairs. In this case, helping one friend by revealing pertinent information harms the other by reducing the likelihood of finalizing the sale.

\section{Whistle Blowing}

Ayers and Kaplan (2005, p. 127): a vignette protagonist overheard a conversation that appeared to describe intentional wrongdoing on the part of outside consultants that would cost a company $\$ 300,000$.

Chiu (2003, p. 68): a manager contemplated "blowing the whistle on major corruption that he has observed in his company”.

Chiu and Erdener (2003, pp. 342-343): a vignette “specifically written for the purpose of this study”, but not described, depicted a situation "involving unethical behaviour in which peer reporting could occur”.

Hansen (1992, p. 527, Scenario 2): an employee of an auto parts firm decided against informing an auto manufacturer about possible quality issues in products being supplied.

Jung (2009, p. 943, Scenario 3): a student surreptitiously took a photo of another student vandalizing school property and posted this on the internet. 
Radtke (2000, p. 310, sixteenth vignette): an employee discovered that a colleague appeared to be pilfering company property and had to decide whether or not to blow the whistle.

Zhang, Chiu, and Wei (2009, p. 30): a bank teller contemplated blowing the whistle after learning that a senior colleague had engaged in embezzlement. 